\title{
HEGEL Y LA TOTALIDAD EN EL TODO
}

\section{HEGEL AND THE TOTALITY IN THE WHOLE}

\author{
Diego Chaverri \\ Universidad Nacional de Costa Rica
}

Recibido: 11 de noviembre, 2013 • Aceptado: 4 de marzo, 2014

Resumen: La filosofía dialéctica de Hegel se despliega particularmente en el concepto de totalidad, el cual permite aprehender la importancia de otros conceptos centrales en sus obras. Este artículo recorre el concepto de totalidad en Hegel e indica algunas de sus implicaciones más allá del optimismo propio de la filosofía clásica alemana, entre estas, su influencia en la sociología.

Palabras clave: Hegel, totalidad, sociology, modernidad, dialéctica

Abstract: Hegel's dialectical philosophy particularly unfolds in the concept of totality, one that allows apprehending the importance of other main concepts in his works. This article covers the concept of totality in Hegel thus pointing some of its implications beyond the German classical philosophy optimism, including his influence in sociology.

Keywords: Hegel, totality, sociology, modernity, dialectic.

\section{Prolegómeno}

El concepto de totalidad en Hegel permite aprehender la importancia de todos los demás conceptos. Se confronta un autor que ha despertado múltiples debates de mayor resonancia, en ese sentido este texto es una invitación a tal debate que hace a Hegel merecedor de un lugar destacado en la historia del pensamiento y en el pensamiento de la historia.

El trabajo no se da fácil, el primer obstáculo es precisamente el debate precedente, autores de diversas épocas, de diversas regiones, y ciertamente 
de distintas corrientes de pensamiento, han discurrido largo y tendido en las encrucijadas de la filosofía hegeliana, no obstante aparece de nuevo la totalidad como concepto capaz de dar cuenta de esta dispersión. El propósito de este ensayo redunda en recuperar el concepto de totalidad en textos de Hegel, y posteriormente plasmar esta misma discusión en la teoría de lo social. Importante como lo anterior, es distinguir el concepto de «todo» del concepto de «totalidad», justamente porque el primero de estos es el que vierte en extrapolaciones como totalitarismo (tendría una función ideológica), mientras la totalidad ofrecería el referente epistémico para hacer la sociedad algo pensable y susceptible de estudio, consistiría en un aporte teórico indispensable, y en ese sentido imprescindible para la teoría sociológica clásica y también contemporánea.

Para cubrir este debate, se da especial importancia a la noción de individuo y sociedad, pues es desde la individualidad activa, agente y no paciente, que se establece un puente con la totalidad, una vía amplia para referirse a la tensión entre lo particular y lo universal.

No se puede dejar de recuperar además el contexto político histórico en que Hegel fue estudiante, donde el idealismo alemán era una teoría de la revolución francesa, una respuesta al reto a la racionalidad que esta revolución representaba, además de ser en el plano estrictamente filosófico una oposición al empirismo británico; con esto ya los enciclopedistas Diderot y D’Alembert habían definido al ciudadano como una persona libre, y Kant remató declarando la igualdad de todos frente a la ley, así el aporte histórico político de Hegel es que su sistema descubrió las implicaciones revolucionarias de las ideas liberales de libertad e igualdad (Marcuse, 1992).

El tema del individuo entronca en todo momento con la totalidad, pues este es siempre el intérprete, así, por defecto al menos, la totalidad depende del grado de autoconciencia del individuo, por eso la preocupación por el concepto de trabajo en frankfurtianos como Marcuse, Adorno y Horkheimer (no así en Benjamin y Fromm), pues a través de la línea que va de Hegel hacia Marx ${ }^{1}$ reconocían los efectos del trabajo alienado sobre

1 Marx, en los manuscritos de 1844, destacó de Hegel el haber reconocido al ser humano como resultado de su propio trabajo: «La grandeza de la fenomenología hegeliana (...) consiste en que capta la esencia del trabajo y concibe a los hombres objetivos, verdaderos por ser hombres reales, como resultado de su propio trabajo» (Marx, 1968, p. 189,190). 
la autoconciencia ${ }^{2}$ del trabajador. La tarea es cubrir el concepto de totalidad desde su singularidad y universalidad, para determinar sus rasgos principales.

\section{Totalidad y singularidad}

La totalidad es el vacío, ${ }^{3}$ es la potencialidad de que algo sea colmado efectivamente en cada singularidad, pues en su momento efectivo la totalidad necesita siempre ser llenada, solo así se concreta, es decir que forzosamente se pasa por cada elemento constituyente, el proceso de la experiencia y sus resultados, y el contenido que es todo lo que se manifiesta, pero solo a través del devenir histórico aprehendido y comprendido. Justo sobre esto Gadamer aclaró que no hay división en Hegel entre forma y contenido, o entre apariencia y realidad, pues: «La apariencia es más bien la totalidad de la realidad» (Gadamer, 1981, p. 57), así la realidad es lo que se manifiesta de alguna manera, por eso también es racional, es un resultado, no es un dato, lo cual le da el rasgo de inteligibilidad, consecuentemente como proceso no es ajeno al individuo, no es externo.

Pero la totalidad no es una cualidad inherente a todas las cosas, es también una categoría necesaria, no surge a priori. Precisamente la lógica de Hegel inicia, en la doctrina del ser, debatiendo el vacío del «ser» como nada, pues la sosería denotativa de la palabreja dice demasiado poco, «ser» no es algo dado, sino que tiene que producirse; justamente para tal efecto está el concepto de motilidad que acotó Marcuse, se debe ejercer acción, producir experiencia, y recuperar ésta en la palabra, pues el lenguaje es el medio cultural más depurado hasta hoy para aprehender la constitución de la realidad, y así es como puede pertenecer al ser humano, sería el devenir trabajado lingüísticamente.

2 Hegel dijo sobre esto: «La conciencia es para sí misma, es la distinción de lo no-distinto, o autoconciencia. Yo me distingo de mí mismo, y así es inmediatamente para mí que esto distinto no es distinto para mí. Yo, lo homólogo, me rechazo de mí mismo (...) en tanto es distinto ya no es ninguna diferencia para mí» (Hegel, 1981, p. 159).

3 Garaudy recogió la siguiente cita de Hegel: «Enseño las palabras inmersas en un encadenamiento caótico y diabólico; cada cual puede interpretarlas a su gusto, pues nada las fija dentro de límites estrechos y los pensamientos que el poeta, inspirándose en las ondas que braman y las rocas escarpadas, presta a su bien amada. En lo que el poeta, como yo, imagina, reconoce y experimenta, cada cual puede encontrar a su gusto el néctar reconfortante de la sabiduría, pues yo todo lo he revelado, haciéndolo surgir de la nada» (Garaudy 1969, p. 35) [subrayado añadido aquí]. Empero, estos episódicos excesos taumatúrgicos en Hegel son los que le permitieron luego a Marx señalar en el filósofo una mistificación de la dialéctica. 
Lo útil de la motilidad a la que se refirió Marcuse es precisamente para destacar la experiencia en la constitución del sujeto, que se da justo en su encuentro con la alteridad, la igualdad consigo mismo en el ser-otro, la negatividad: «Esta quebradura y escisión esencial del ser es su fundamento como motilidad, como acaecer; ella fundamenta la multiplicidad del ente como modos varios del ser» (Marcuse, 1970, p. 50) y su concepto consustancial sería el del ser semoviente, en tanto el ser aporta la mediación a través de la autoigualdad como ser para sí, ${ }^{4}$ e inicia allí su explicitación. «Como todo ente es sólo en el ser-otro, en la negatividad de sí mismo, tiene necesariamente que ponerse a prueba y afirmarse en la alteridad como aquello que él es» (Marcuse, 1970, p. 50), que sería devenir otro siendo simultáneamente consigo mismo, sin escisión, «la diferencia del ser se agudiza aún en ese acaecer del algo que es ahora acaecer concreto en la referencia ontológica a lo otro» (Marcuse, 1970, p. 60); esto es, la alteridad es del ser para sí que establece el vínculo con el ser-otro, implica una resistencia y por tanto un movimiento por superarla progresivamente; el problema es que esta determinación o diferencia determinante se extendería al infinito, y así sucedería si no se regresara de nuevo al ser renovado en su acaecer, algo que Hegel anotó al captar el espíritu histórico.

La totalidad no es conocerlo todo, como podría ser en Kant, especialmente porque su síntesis trascendental sería rápidamente abandonada por él mismo, es decir que abandonaría el principio de lo cognoscible por el sujeto y establecería la diferencia entre fenómeno y mundo suprasensible, así Kant recaería en la filosofía del entendimiento y no del sujeto. Por eso Hegel comenzó trabajando el concepto de ser, antes pasando por Descartes, que si bien fue pionero del pensamiento moderno, a su noción del ego cogito le falta el yo enfatizado como sujeto activo, más que como sujeto pensante (Kojève, 1993) y la actividad solo se comprende históricamente.

Es harto importante este aspecto, pues Hegel contiene una filosofía del individuo que halla su sustancia en el asidero social, es decir que no se agota en el yo, a pesar de que es a través del sujeto que se establece un vínculo con la totalidad, por eso es importante aquí una prelación para explicar dicho entronque; pues, por ejemplo, un antecedente como el nosce te ipsum de la filosofía griega, con la que algunos vinculan a Hegel, tiene muy poco alcance.

4 O también el yo = yo que Hegel tanto denunció en la Fenomenología. 
Kojève fue contundente, y para este el ser en Hegel es verdadero solo en su devenir histórico, y a través de la acción que niega lo dado, a través de la lucha y el trabajo (Kojève 1993), es decir que el sujeto no posee condición inherente de individualidad, sino que tiene que defenderla en el proceso de constituirla, tanto así que el ser incapaz de poner en riesgo su vida por defender un prestigio que no sea vital no es verdaderamente un ser humano, ${ }^{5}$ pues a nivel del deseo el ser humano debe ponerlo ante los otros deseos y demostrar la vigencia y factibilidad del suyo (Kojève, 1993), ahí el fruto de su lucha y trabajo, el acceso al reconocimiento del deseo, esto resalta también al entender el deseo como antropógeno, es desear de modo humano (Fragomeno, 2012, p. 20).

Hegel lo planteó epistemológicamente como la tensión entre lo subjetivo y lo objetivo, un momento que debe superar su mera formalidad en el proceso de trasladar la objetividad a la subjetividad por medio de la actividad realizada en un espacio y momento, pues la mera subjetividad no suple las necesidades, así como la mera objetividad sería en realidad pura determinación, quietud (Hegel, 1999); la subjetividad deviene objetiva únicamente cuando realiza su fin (Hegel, 1999). Todo es mediación y la voluntad debe ejercitarse allí para constituirse como tal: «Una voluntad que no decide nada no es una voluntad real» (Hegel, 1999, p. 93). Punto de giro para replantear el vínculo necesario del reconocimiento individual en el plano de su concreción universal, "por eso lo que quiera decir en adelante lo subjetivo u objetivo de la voluntad debe ser iluminado en cada caso a partir de la conexión que por su posición guarda con la totalidad» (Hegel, 1999, p. 104), precisamente porque la universalidad de la reflexión es la totalidad; la dialéctica por su parte sería el desarrollo y progreso, la lógica del movimiento que pone en marcha al concepto (Hegel, 1999), esto ciertamente rebosa optimismo.

El individuo tampoco está fuera de sí mismo, como apareció en el racionalismo, ni está supeditado a constricciones extrañas, esto es, no se tiene un cuerpo, se es en él, «soy en mi cuerpo»(Hegel, 1999, p. 132), «soy viviente en este cuerpo orgánico que es mi existencia exterior indivisa» (p. 131). El individuo contiene el derecho abstracto, «al privarlo de la vida se le negaría

5 A propósito de la doctrina del concepto, Hegel terminó apuntando a la mitología como puente hermenéutico y el mito contiene una forma de objetivación de la experiencia social humana (Cassirer, 1964). 
la totalidad de su libertad» (Hegel, 1999, p. 224); la libertad subjetiva es un rasgo fundamental para el advenimiento de la modernidad, y el cuerpo es y está en este devenir, «la vida, por ser la totalidad de los fines, tiene derecho ante el derecho abstracto (...) La particularidad de los intereses de la voluntad natural resumida en su totalidad simple es la existencia personal en cuanto vida» (Hegel, 1999, p. 223). Se trata de derechos individuales que no pueden prescindir de la totalidad social y cultural como vinculante, es decir, tanto lo particular como lo universal contienen la totalidad, así también cada momento individual y universal está articulado en la totalidad, tiene esta semejanza que le permite entablar tensión y, en el sujeto, actividad.

El vínculo autorreferencial se torna más complejo justo en el momento en que el individuo se constituye persona, y extiende su subjetividad sobre propiedades, multiplica las posibilidades de vincularse con otras personas y sus propiedades, lo cual sería participar en la sociedad civil; pero incluso antes hay un momento de la totalidad en la familia, allí «el individuo ha eliminado su esquiva personalidad y se encuentra con su conciencia en una totalidad» (Hegel, 1999, p. 114).

Sobre el individuo y su inscripción en el todo, Garaudy lo dijo irrevocablemente, pues para él Hegel invitó a «tomar conciencia de que el mundo engendra las ideas y no la Idea el mundo» $(1969$, p. 31); se trata entonces de ideas del mundo y en el mundo, aunque ciertamente pueden no ser para el mundo. Así, mientras el lenguaje media entre el concepto y la conciencia,

Marx, recogiendo la rica herencia de esta dialéctica, ha mostrado que el concepto no era el grado más elevado de conocimiento: más allá está la práctica. La práctica tal como la concibe Marx, no sólo es lo contrario del concepto, sino que lo integra a ella, con todo el conocimiento sensible y todo el conocimiento racional, como uno de los momentos (Garaudy, 1969, pp. 31-32).

Lo importante aquí es destacar sobre todo que la praxis es vinculante con la totalidad por su potencial integrador, pues entendido dialécticamente no hace una distinción de trincheras entre teoría y práctica, sino que ambas se asumen desde su aporte a la complejidad del mundo: ${ }^{6}$

6 Gadamer señala sobre la dialéctica: «En cuanto tal es por necesidad pensamiento conjunto de determinaciones contradictorias» (1981, p. 31). 
Resulta así como consecuencia que el devenir filosofía del mundo es al mismo tiempo el devenir mundo de la filosofía, que su realización es a la vez su pérdida, que lo que ella rechaza hacia el exterior es su propia deficiencia interna, que precisamente en la lucha ella cae en los defectos que combate en su contrario, y que elimina tales defectos sólo cayendo en ellos» (Garaudy, 1969, p. 37).

La totalidad de la singularidad es superada, «en su conjunto, la determinación de la subjetividad de la voluntad es a su vez una totalidad que, en cuanto subjetividad, debe tener también objetividad» (Hegel, 1999, p. 201), es decir, su concreción es una pugna, la contraposición y resolución última entre la subjetividad y la objetividad reside en la actividad (Hegel, 1999). Asimismo, la otredad es asidero social y fuente de objetividad, y es distinta esta relación con objetos a la relación con otros sujetos, la resistencia del objeto es inmediata, la resistencia de otro sujeto es mediada por su actividad, por tanto más rica y compleja. Ahora se pasa a discutir el producto de la actividad, la conservación sistémica del reconocimiento entre los sujetos y las relaciones que mantienen entre sí y sus objetos.

\section{Totalidad y universalidad}

Concisamente para Hegel: «La cosa, en efecto, no se agota en su fin, sino que se encuentra en su desarrollo, ni el resultado es el todo actual, sino que está unido con su devenir» (1991, p. 69); el todo no subsume a la experiencia, sino que permite a la misma manifestarse, de tal forma el conocimiento último es el auto-conocimiento en el todo, eso sí, Hegel era exigente: «Tampoco el concepto alcanzado del todo es el todo mismo» (1991, p. 73), es decir que la categoría no agota el todo, pues la categoría en el mismo momento de agrupar se disuelve en el tiempo, pues es un predicado con alcance hacia el pasado, por eso su actualidad se halla en el sujeto, a quien corresponde la tarea de comprender y revitalizar los conceptos a través de la práctica, «todo depende de aprehender y expresar lo verdadero, no como sustancia, sino también precisamente como sujeto» (Hegel, 1991, p. 76). Por eso desde el inicio se insiste en la complementariedad intrínseca en el concepto de totalidad para poner en una misma trama semántica (comunicable) conceptos como dialéctica, negación, trabajo, sujeto, verdad, 
ser, concepto y libertad, entre otros que pueden perderse al permanecer en la misma totalidad.

«Lo verdadero es el todo. Pero el todo es sólo la esencia que se completa a través de su desarrollo. De lo absoluto es necesario decir que es esencialmente resultado, que es al fin lo que es en verdad» (Hegel, 1991, p. 77), lo anterior quiere decir que si el todo es en esencia desarrollo, quien lleva a cabo tal tarea es el sujeto, por esto lo verdadero es sujeto, aquí el juego dialéctico ${ }^{7}$ insinuado en estos dos primeros segmentos del artículo, entre lo singular y lo universal, pues la totalidad es para el sujeto (singular) y el sujeto verdadero solo se puede realizar en la totalidad (universal), precisamente porque la totalidad lo niega y lo empuja, es la motilidad, lo mueve a manifestar su deseo y defenderlo en lucha, hacer de este su concepto y darle contenido liberador en la práctica, pero solo a través de la historia que ha llegado al momento en que es posible tal exhortación y su correspondiente volición, este es un punto de actualidad total, donde se abre el debate sobre las promesas de la modernidad, al respecto Hegel siempre fue optimista como ya se indicó, pero no ingenuo, pues la perfectibilidad «ha de pensarse como tarea absoluta, es decir, tal como ella permanece sencillamente, una tarea a cumplir (...) lleva a contradicciones, contradicciones de una tarea que debe permanecer tarea, y sin embargo ser cumplida» (Hegel, 1991, p. 390). Igual sucede con la reconfiguración de la subjetividad y la objetividad por medio de la actividad, la materia trabajada luego pasa a ser trabajo apropiado (Hegel, 1999), pero esto no agota la necesidad de trabajar.

Ahora bien, la apropiación es conflictiva y abarca la constitución del individuo mismo, «la dialéctica del concepto y de la conciencia todavía sólo inmediata de la libertad provoca la lucha por el reconocimiento y la relación de señorío y servidumbre» (Hegel, 1999, p. 142); luego entra la mediación del Estado, y el reconocimiento no supondría siempre una lucha directa. Pero el individuo debe oponer resistencia y desplegar su actividad sobre la apropiación, de otro modo sería enajenado, siendo esto contraproducente en el extremo. Señaló Hegel que «con la enajenación de todo mi tiempo concreto de trabajo y de la totalidad de mi producción, convertiría en propiedad de otro lo sustancial

7 Hegel usualmente se ilustraba a sí mismo con la figura del círculo, luego algunos optaban por la espiral o incluso la triada, todas estas estructuras están muy presentes, y siempre tienen en común una clara propuesta de superación del pensamiento binario, lineal o dicotómico, pero sería más interesante, aunque aun difícil en su expresión gráfica, pensar en la figura de una vorágine, para darle una dimensión de profundidad, tal como se aprehende la realidad. 
mismo, mi actividad y realidad universal, mi personalidad» (1999, p. 154); precisamente ejercitar el derecho abstracto (individual) supone concretarlo en el reconocimiento, esta es la veta crítica, anticonservadora, en Hegel.

Un balance provisional lo proveyó Hegel, «la totalidad de las exteriorizaciones de una fuerza es la fuerza misma, la totalidad de los accidentes la sustancia, la totalidad de las particularidades lo universal» (1999, p. 154), aquí se valió de la misma operacionalización del concepto de totalidad para explicar otras categorías, pues la totalidad, una y múltiple a la vez, abarca a la actividad toda y por ello mismo es modificada constantemente dentro de sí, nada puede quedar fuera en la modernidad; esta es la realización de la totalidad, y torna el derecho concreto a través de una institución que se funda sobre las exteriorizaciones de la fuerza, sobre el trabajo acumulado; el Estado no anula la pugna por el reconocimiento, «es necesario pues que haya conflictos puesto que estamos en el estadio de lo finito» (Hegel, 1999, p. 177), el Estado simplemente se manifiesta como un momento de autoconciencia del conflicto, que ahora es apropiada y se inscribe en la cultura, y de nuevo,

La cultura es por lo tanto en su determinación absoluta la liberación y el trabajo de la liberación superior (...) Esta liberación es en el sujeto el duro trabajo contra la mera subjetividad de la conducta, contra la inmediatez del deseo, así como contra la vanidad subjetiva del sentimiento y la arbitrariedad del gusto. El que este trabajo sea duro constituye parte del poco favor que recibe (Hegel, 1999, p. 309).

Teniendo como resultado la reunión de los individuos singulares desde sus necesidades y a todos como sociedad a través del trabajo, que va unido también al deseo.

Otro que podría asentir sobre lo mismo es Marcuse, para quien el trabajo es actividad de mediación entre el mundo objetivo y el mundo subjetivo, permite generar una condición en la que se puede superar el extrañamiento en que aparecen las cosas como dadas, al apropiárselas cuando se dan como trabajadas (Marcuse, 1992).

Así también cada cual deviene universal y miembro de una comunidad, es decir forma parte de un todo solo a través de su especificidad, pues sino es absorbido por el todo y su individualidad se diluye en el no-reconocimiento, 
como sucede con la conciencia infeliz en la Fenomenología, pero para Marcuse el concepto de trabajo es lo central en Hegel, en cambio el Volkgeist es un ejemplo que podría llevar a otra ruta de pensamiento, pues tal espíritu del pueblo es la historia de liberación de un pueblo, y si bien esta liberación solo se da por medio del trabajo y de la lucha, el trabajo no siempre produce libertad. Bien se reconocen resultados insidiosos del trabajo en la modernidad, pero también se debe acotar la importancia del trabajo para mediar la añeja determinación natural de la escasez, y en esto Marcuse (1992) aportó que la sociedad productora de comodidades es preferible porque se da en un estadio superior de desarrollo histórico que implica el reconocimiento de los derechos individuales, así para Hegel la humanidad había llegado al punto de madurez intelectual necesaria para hacer efectiva la razón en su despliegue histórico y esto debido a que asume que la sociedad burguesa había llegado a una forma adecuada a los principios de la razón ${ }^{8}$ (Marcuse, 1992).

La cumbre de este despliegue del trabajo sería ética y por ello se realiza en una institución social, «el desarrollo de las relaciones que resultan necesarias por la idea de su libertad y son por lo tanto efectivamente reales en toda su extensión en el Estado» (Hegel, 1999, p. 268). Ya se ha mencionado la proximidad entre la necesidad y la actividad, «en efecto, el hombre es actividad en la medida en que hay algo que no ha alcanzado y quiere producirse y hacerse valer en referencia a ello» (Hegel, 1999, p. 273). Allí está la imperiosidad del despliegue dialéctico de la historia, el trabajo llegado al punto de crear una institución para la autoregulación, el individuo y el Estado no son ajenos el uno al otro, al observar el cumplimiento de sus deberes el individuo participa de los derechos que salvaguarda y garantiza el Estado, «si todos los derechos estuvieran por un lado y todos los deberes por otro, la totalidad se disolvería» (Hegel, 1999, p. 275). Por ello es determinante que haya una institución que concretice la subjetividad, y para Hegel le corresponde al Estado, como la más esplendorosa institución de la sociedad burguesa. «El hombre tiene por ello su efectiva vida sustancial en

8 Marcuse en sus primeros escritos fue optimista, al igual que Hegel, pero el frankfurtiano tomó una veta de carácter kantiana en este aspecto, pues la estructura de pensamiento sería uniforme en todos los sujetos pensantes y, más aún, para Marcuse de esto se sigue que el individuo es necesariamente libre (Marcuse, 1992); es correcto decir que el sujeto no está atado a lo dado y es capaz de trascender, pero no es necesariamente libre, aunque su libertad sí es una necesidad e incluso aparece como constituyente fortísimo de la subjetividad de cualquier individuo. 
el Estado, la ciencia, etcétera, y en general en la lucha y el trabajo con el mundo exterior y consigo mismo» (Hegel, 1999, p. 286).

A pesar de la imposibilidad de ver en Hegel una crítica al Estado por su forma burguesa y en connivencia con el capitalismo, nunca renuncia a la resistencia y la actividad como condición necesaria de existencia para que el individuo se constituya como moderno, también por esto es que el idealismo de Hegel contiene un realismo, pero no analítico, sino concreto, histórico y social.

El vínculo entre la singularidad y la universalidad está en la forma del ciudadano inscrito en un espacio y un tiempo, modernos, en donde hay soberanía de la que se desprende la posibilidad de la actividad autónoma, expresó Hegel (1999) que la persona concreta es una totalidad de necesidades en tanto participa de la sociedad civil, precisamente porque la totalidad es en donde se dirime la mediación, allí el reconocimiento es «el momento que convierte a las necesidades, los medios y modos de satisfacción, en su singularidad y abstracción, en algo concreto, en cuanto social» (Hegel, 1999, p. 314). Para Hegel no había ambages aquí, «todo lo particular deviene social» (Hegel, 1999, p. 315) y el momento social contiene una parte de la liberación, precisamente el momento en el que lo realiza en el mismo movimiento que le da concreción.

No habría ruptura entre método dialéctico y sistema dialéctico, pues el método apuntaría al cambio y el sistema a la conservación, esto estaría fundamentado en la premisa de que no hay nunca una conservación absoluta ni un cambio a partir de la nada, «es la razón inmanente al sistema de las necesidades humanas y a su movimiento lo que lo articula en una totalidad orgánica de elementos diferentes» (Hegel, 1999, p. 320). Nótese de esta manera cómo el concepto de totalidad no solo es necesario para explicar los demás conceptos, sino que los demás conceptos son igualmente necesarios para explicar la totalidad. Así la totalidad es dialéctica, permanece en el cambio, en su momento de conservación, por ejemplo «el ámbito de las leyes debe ser por una parte una totalidad cerrada y terminada, mientras que por otra es la continua necesidad de nuevas determinaciones legales» (Hegel, 1999, p. 336).

Nada oculta el optimismo de Hegel, pues el Estado respiraría racionalidad y modernidad por todos sus poros, «el Estado en y por sí es la totalidad ética, la realización de la libertad» (Hegel, 1999, p. 375), o dicho de otra forma «el 
Estado es el espíritu que está en el mundo» (p. 390). El criterio de partida se puede aceptar, «la verdadera realidad es necesidad: lo que es efectivamente real es en sí mismo necesario» (Hegel, 1999, p. 404), es decir, el Estado es el resultado de un proceso de actividad humana realizando el concepto, pero no hay todavía en donde escrutar su sostenibilidad, en efecto «el principio del mundo moderno es la libertad de la subjetividad» (Hegel, 1999, p. 417) y según él alcanzaría su mayor despliegue en el Estado moderno, esto simplemente no es absoluto:9 «El Estado concreto es la totalidad articulada en sus círculos particulares» (Hegel, 1999, p. 459), y precisamente la particularidad no está obligada a una articulación dada, la puede modificar.

Finalmente se pluraliza el Estado para que despliegue su potencial de injerir sobre la universalidad al oponerse a otros Estados, y de nuevo Hegel fue optimista, «los Estados autónomos son, por el contrario, fundamentalmente totalidades que se satisfacen a sí mismas» (Hegel, 1999, p. 485). Bien se habla ahora de totalidades, pero actualmente esta sentencia sobre la autosuficiencia estatal ha perdido vigor; justamente para combatir la tasa decreciente de enriquecimiento se expanden las fronteras, consecuentemente los Estados resultarían menos autónomos y se regirían ahora por el juego de las totalidades que ya no están cerradas en sí y constituyen parte de la totalidad universal, tensada por conflictos de alcance internacional.

La materialización del concepto de totalidad en Hegel se concreta por vía de la lógica dialéctica, tal y como se recupera en el marxismo en línea con autores como George Novack. La lógica dialéctica surgió por oposición a la lógica formal, es de nuevo la lógica de la contradicción inherente, se conoce algo cabalmente al conocer su opuesto, aunque habría que considerar si todo tiene un opuesto claro, no obstante, para el criterio de Novack la dialéctica hegeliana todavía está limitada por su idealismo, por eso apuntó que Marx y Engels lograron expurgar lo místico de la dialéctica hegeliana al darle asidero material; el error de Hegel fue pensar una totalidad que se llega a cerrar (Novack, 1977), convirtiéndose en un todo, por eso él mismo no fue claro en distinguir ambos conceptos, pero su virtud consistió en que

9 Un punto ciertamente enclenque en Hegel es i.e. su defensa del orden natural de selección por abolengo; desde su posición política favorable a las monarquías constitucionales conserva lo antiguo en el monarca y añade lo moderno vía constitución, pero subsume un proceso civilizatorio a arbitrariedades parapetadas en criterios biológicos: «El poder del príncipe contiene en sí mismo los tres momentos de la totalidad» (Hegel, 1999, p. 419), pero allí no hay totalidad, solo la representación de un todo. 
a pesar de ser ocasionalmente un idealista reaccionario, terminaba siendo un dialéctico revolucionario (Novack, 1977), es decir, Hegel mismo encarnaba una contradicción que era clave para comprender su pensamiento.

Lo importante de estudiar, mediante la lógica dialéctica, la totalidad es que asume un universo no estático, la realidad no es permanente, fluye y cambia, la verdad es concreta y susceptible de ser inteligible, racional en ese sentido. El poder hermenéutico de la totalidad es uno que, tal como indicó Nahuel Moreno (1981), permite comprender que las contradicciones están unidas en esta misma totalidad, más aun, aplica el concepto para poder explicar la manifestación del capitalismo en la sociedad como totalidad que quiere actuar como un todo, un fenómeno que en su devenir muestra el proceso de la totalidad.

\section{Totalidad hermenéutica, epistémica y óntica}

En palabras de Marcuse, «el ente finito no tiene historia, sino que es historia» (1970, p. 63) y lo finito como ideal conforma a su vez el idealismo. Para Marcuse esto implica un principio ontológico hegemónico en el idealismo, pero una lectura divergente se puede hallar en la Fenomenología, pues se recupera el principio epistemológico y el ontológico, y a su vez un principio hermenéutico, en este último está el vínculo y la importancia de la historicidad contenida en el ser, al saberse ser cognoscible y cognoscente. En Hegel, finalmente, esto no se vierte en historicismo, «Hegel ha determinado la historicidad como comportamiento destacado de la autoconciencia en su motilidad» (Marcuse, 1970, p. 314). Pero habría que añadir a Marcuse que también la historia determina la autoconciencia como potencial y efectiva, pero en ningún caso se trata de la historia como disciplina abocada a la documentación del pasado, sino como el acaecer interpretado en el presente por el sujeto moderno, allí estaría el rasgo hermenéutico, luego el rasgo epistémico se manifiesta como la determinación en un momento histórico que posibilita los modos del pensar, y finalmente el rasgo óntico sería la experiencia de la conciencia como constitutiva del individuo moderno.

Todo este proceso no es gratuito, se insiste desde la Fenomenología, implica un proceder epistémico y óntico, es decir, le va la vida en ello al individuo para comprenderse en su actuar, en donde «hay que soportar la 
duración del camino, pues cada momento es necesario; por otra parte es indispensable detenerse en cada momento porque cada uno es él mismo una figura total individual» (Hegel, 1991, p. 82). De nuevo el total individual solo se da en su movimiento, y tal movimiento para captarse a sí mismo solo se logra cuando se reconoce, en lo otro, lo mismo y lo propio; así la diferencia nunca es insalvable, es por el contrario un vínculo, el conflicto entendido como oportunidad de actuar sobre las cosas al captar el potencial de reconocimiento en el despliegue de la subjetividad, «esa es la prodigiosa fuerza de lo negativo; es la energía del pensar, del yo puro» (Hegel, 1991, p. 84). Es la resistencia a la muerte como absoluto, la muerte como quietud.

Hegel remató contundentemente: «La cosa es yo; de hecho en este juicio infinito la cosa es superada: la cosa es nada en sí; sólo tiene significado en relación únicamente a través del yo y su referencia al yo» (1991, p. 485). Garaudy insistió en el mismo punto, en un concepto que captara el saber absoluto, no como sabiondez, sino como saberse situado, producido, productor y reproductor, se preguntó entonces:

¿Pero qué es la Idea Absoluta? Ella se supera, a su vez, a sí misma si no quiere recorrer de nuevo y desde el principio todo acto de la abstracción y no quiere contentarse con ser una totalidad de abstracciones o la abstracción que se aprehende a sí misma (Garaudy, 1969, p. 74).

Es decir que el movimiento es algo más complejo que decir yo sé, implica la vuelta a la totalidad desde un punto que nunca es total, pues no habría distinción que pueda ser captada si todo es igual al yo. También la totalidad se modifica por el movimiento en la historia, la no naturalización de la condición humana, cualquiera que esta sea, por eso Hegel señaló que se trata de una tarea que debe ser acometida y sin embargo quedar pendiente. Adorno explicó con acierto que:

Criticar el todo como todo sería abstracto, «sin mediación», y dejaría de lado el motivo fundamental de la filosofía hegeliana: que no cabe destilarla de ninguna «sentencia», de ningún principio general, y sólo se acredita como totalidad, en la concreta complexión de todos sus momentos (1981, p. 16). 
Dejó también la tarea planteada,

Por lo que únicamente honrará a Hegel quien sin dejarse intimidar por el pavor ante la enredosidad poco menos que mitológica de un proceder crítico que aquella totalidad parece volver falso en todos los casos, en vez de otorgarle o denegarle, favorable o desfavorablemente, méritos, persiga el todo tras del cual él mismo iba (Adorno, 1981, p. 16).

Eso sí, la concepción hegeliana de tiempo es prioritariamente en pasado y presente, pero también el futuro como utopía entra en la dialéctica, quizá para Hegel, por su marcado optimismo, era preclara la proyección a futuro, y esto no le preocupaba en tanto tenía arraigo en un pasado que se superaba en su movimiento y no lo debatió a futuro, esto no preocupó a Hegel, pero precisamente como la superación conserva las distintas figuras de la conciencia, la modernidad está situada en una abundancia de figuras de la conciencia y todas tienen el potencial de establecer augurios, destino, utopía o mera supervivencia. Así el concepto de totalidad desbordó al mismo Hegel.

Es primordial que en Hegel no hay un tal a priori, o lo que es igual, lo a priori es asimismo a posteriori (Adorno, $1981^{10}$ ), quizá por esto mismo no le preocupó el apriorismo (que por supuesto no es tal) que se puede dar al futuro, precisamente porque la libertad es constituyente de la subjetividad, se permite una extensión a un futuro, es de nuevo el tema de la tarea que no es un hecho, hacer efectiva a la razón, a la que se ha accedido históricamente, es una misión.

Adorno continuó con el tema y dijo de Hegel, «su todo es, en definitiva, solamente el dechado y quintaesencia de los momentos parciales, que en cada instante remiten fuera de sí mismos y brotan, disociándose unos de otros; no es nada que estuviese más allá de ellos» (1981, p. 19). Esta es en efecto la categoría de totalidad, captada en una subjetividad que se entiende a sí misma como tal y consecuentemente elude caer en lo abstracto de juicios unilaterales, además de estar siempre situada históricamente, que es al mismo tiempo el movimiento, así se comprenden también las lecturas dispersas que han hecho varios lectores de Hegel, incluso las más conservadoras (también

10 «Hegel perdió confianza en el fatal legado de la metafísica tradicional, en la pregunta por un último principio» (Adorno, 1981, p. 24); «la elección del punto de partida, de lo que en cada momento sea lo primero, es indiferente para la filosofía hegeliana» (p. 28). Así como la misma Fenomenología comienza por el final (el prefacio). 
conocido como el hegelianismo de derecha), y sucede que «la dialéctica, una vez limpia del fermento crítico, se presta al dogmatismo» (Adorno, 1981, p. 23); precisamente por estar en el todo como un particular es vulnerable de ser absorbida como un pensamiento y por tanto anulada, pero la dialéctica es a su vez una herramienta para superar este oficialismo del pensamiento, «la dialéctica (...) es un impertérrito afanarse por obligar a que se emparejen una conciencia de la razón crítica de sí misma y la experiencia crítica de los objetos» (Adorno, 1981, p. 25).

Una vez más, respecto al individuo, Adorno (1981) aclaró que el yo se opone al ser, aquel es la patria del conocimiento; el ser es cualquier cosa, el yo es todo lo que no es cualquier cosa, es todo lo demás, por eso es el sujeto quien introduce determinación, pues como absoluto no resolvería jamás los momentos empíricos, así se da posicionamiento teórico al sujeto activo trascendental que desde lo empírico lo supera, y la universalidad estaría en el trabajo colectivo, y multiplicado también por el trabajo acumulado sería la totalidad, esa misma que escapa a cualquier aprehensión literaria, incluso esta, una definición que sin embargo implica también un trabajo, es decir, un poco de totalidad; pero esto se debe decir con muchísima cautela, pues se podría recaer en una metafísica del trabajo.

La ambigüedad de la sociedad burguesa está en que sustituye unas leyes por otras, deificándose en el proceso, «a esta sociedad, el ser humano en cuanto productor libre de ataduras le parece autónomo, heredero del legislador divino, virtualmente todo poderoso; pero, al mismo tiempo, el individuo singular resulta ser, por tanto, algo totalmente impotente y anulado» (Adorno, 1981, p. 68). Así las lecturas de Marcuse y Adorno son divergentes en este punto, y aquí se apunta a la de Adorno, pues él entendió que la figura hegeliana consistía en que «nada puede entenderse aislado, todo únicamente en conjunto» (1981, p. 121). La totalidad no es estrictamente parte de un sistema, sino parte de un método para comprender.

A modo de consideración final, el concepto determinante y determinado en Hegel es el de totalidad por dar una base lo suficientemente maleable y estable a la vez, en la cual se pueden reunir los demás conceptos, y donde las oposiciones serían momentos. Para algunos autores el eje central para entender la obra y alcance todavía vigente de Hegel es el trabajo, para otros la dialéctica, para otros la negación, para otros la idea, o el espíritu, y así sucesivamente 
todos están en lo cierto, o lo que es lo mismo, cada uno se equivoca, pues en la totalidad, en tanto se oponen unos a otros, permanecen en la lucha por el reconocimiento y se hacen conceptos humanos, ahí está el contenido de su verdad y la comunicabilidad de su juicio, la totalidad no hace distinciones, o lo que es igual, las hace todas, pues contiene en sí el campo de lo posible, cuya frontera es una vorágine en la que se pierden todas las cosas para luego hallarse en el centro, esto tiene fuertes implicaciones epistemológicas, pues en Hegel un conocimiento cualquiera siempre apunta a otro conocimiento, es decir que la soledad de una verdad hipostática irrefutable no es más que un aislamiento inconsciente que presupone acabado el mundo.

El alcance de la filosofía hegeliana para comprender la relación tensa entre el individuo y la sociedad moderna, se ve bien reflejado en la teoría sociológica, no hay aquí un inventario exhaustivo, sólo una provocación. Los autores reconocidos ampliamente como clásicos de la teoría sociológica, Karl Marx, Max Weber y Émile Durkheim, se ven influenciados directa o indirectamente, el caso de Marx es quizá el más explícito, ya antes se aludió a esto. En el caso de Max Weber, está la influencia que recibió de Wilhelm Dilthey, quien trabajó sobre Hegel directamente (Dilthey, 1990) ${ }^{11}$; pero Weber también se nutrió de la discusión sobre la historicidad en los neokantianos, inducida en buena medida por Hegel y continuada en los trabajos de Heinrich Rickert y Wilhelm Windelband (Larroyo, 2004), entre otros. En Durkheim es un poco más difícil rastrearlo, pero no imposible, una de sus influencias decisivas, Charles Renouvier, es reconocido como uno de los filósofos que introduce a Hegel en Francia (Larroyo, 2004), incluso adepto a éste en sus inicios filosóficos (Burrow, 1999, p. 48), pero lo más llamativo aquí es ver como el concepto de totalidad llega incluso a impactar a Durkheim: «La vida no se divide; es una sola y por ello no puede tener más asiento que en la sustancia viviente en su totalidad. La vida está en el todo, no en las partes» (Durkheim, 1976, p. 77), de modo tal que la sociología es potenciada teóricamente por la tradición hegeliana, en sus orígenes y con alcances vigentes.

Hegel suele ser considerado como un filósofo complicado u obscuro, pues se adentra en ese vórtice del que nadie sale igual: la autoconciencia histórica de todo cuanto se experimenta en un movimiento cuya promesa

11 Para muestra su artículo de 1905 Die Jugendgeschichte Hegels und andere Abhandlungen zur Geschichte des deutschen Idealismus (Dilthey, 1990). 
es mantener una travesía, y eso es más importante que salir para siempre del laberinto, pues la lógica de la totalidad tiene sentido en la unidad fugaz en el sujeto como parte del todo. Así la totalidad está contenida en el todo y a su vez lo contiene todo, pues la tensión entre ambos conceptos es que el todo es la abstracción que se concretiza como sistema para conservar los momentos del despliegue de la razón, mientras la totalidad aporta el método para ejercer trabajo consciente y así realizar el todo como idea, una lógica del vínculo como totalidad, pero cuando la alternativa conservadora es quitar la totalidad del todo, esto toma la forma concreta de sociedades totalitarias, tal y como se experimenta en la modernidad tardía, la modernidad vuelta contra sí misma que se quiere conservar fuera del reconocimiento, es a esta modernidad conflictiva a la que renuncian ingenuamente los posmodernos, ignorando el carácter relacional de lo social. Totalidad para quien se las pueda apañar con ella.

\section{Referencias}

Adorno, T. (1981). Tres estudios sobre Hegel. España: Taurus Ediciones.

Burrow, R. (1999). Personalism. A critical introduction. Inglaterra: Chalice Press.

Cassirer, E. (1964) La función del mito en la vida social del hombre. En: Horowitz, I. Historia y elementos de la sociología del conocimiento. Argentina: Editorial Universitaria de Buenos Aires.

Dilthey, W. (1990). Gesammelte Schriften. Alemania: Editorial Teubner.

Durkheim, E. (1976). Educación como socialización. España: Ediciones Sígueme.

Fragomeno, R. (2012). El obstáculo y la inquietud. Cinco estudios sobre Hegel. Costa Rica: Editorial Arlekín.

Garaudy, R. (1969). Textos sobre Hegel. El problema hegeliano. Argentina: Ediciones Calden. Gadamer, H. (1981). La dialéctica de Hegel. España: Ediciones Cátedra.

Hegel, G. (1991). Fenomenología del espíritu. Argentina: Editorial Rescate.

Hegel, G. (1999). Principios de la filosofía del derecho. España: Editorial Edhasa.

Kojève, A. (1993). Introduction to the reading of Hegel. Lectures on the Phenomenology of Spirit. Estados Unidos: Cornell University Press.

Larroyo, F. (2004). Estudio introductivo y análisis de la Enciclopedia de las Ciencias Filosóficas. México: Editorial Porrúa.

Marcuse, H. (1970). Ontología de Hegel y teoría de la historicidad. España: Ediciones Martínez Roca.

Marcuse, H. (1992). Reason and Revolution. Hegel and the Rise of Social Theory. Estados Unidos: Humanities Press International.

Marx, K. (1968). Manuscritos: economía y filosofía. España: Alianza Editorial.

Moreno, N. (1981). Lógica marxista y ciencias modernas. México: Ediciones Xólotl.

Novack, G. (1977). Introducción a la lógica dialéctica. Colombia: Editorial Pluma. 